\title{
MINIMIZATION OF PHENOL AND AMMONIACAL NITROGEN IN REFINERY WASTEWATER EMPLOYING BIOLOGICAL TREATMENT
}

\author{
M.R. Silva, M.A.Z. Coelho; \\ O.Q.F. Araújo \\ Escola de Química / UFRJ \\ Centro de Tecnologia, Bl.E, lab.113 \\ Cidade Universitária, 21949-900, \\ Rio de Janeiro - RJ, Brazil \\ e-mail: rmicheleramos@ hotmail.com, \\ alice@eq.ufrj.br,ofelia@eq.ufrj.br
}

\begin{abstract}
Wastewater from refineries is usually characterized by presence of phenol and ammoniacal nitrogen. The aim of this work was to search for a refinery wastewater minimization employing a biological technology to reduce these pollutants. Experimental data was obtained by treating a synthetic wastewater in a sequencing batch reactor (SBR) operating on different operational schemes for batch scheduling. COD, nitrate, ammonia, phosphate and phenol were monitored as well as dissolved oxygen, $\mathrm{pH}$, level and redox potential through a supervisory control software. Reductions of $95 \%$ were achieved for different concentrations of $\mathrm{NH}_{4}^{+}$and phenol, providing an effluent acceptable by Brazilian environmental legislation.
\end{abstract}

Key words: phenol, refinery, wastewater treatment

\section{INTRODUCTION}

Wastewater from a petrochemical industry usually contains hazardous chemicals, as hydrocarbons, phenols and ammoniacal nitrogen among others. Due to its chemical composition and concentration, their effects on the environment are not desirable (eutrophication, e.g.) as well as dangerous to human health.

Biological nitrogen removal, consisting of nitrification and denitrification, is generally believed to provide the most economical means of controlling nitrogen in wastewater effluents. Nitrification is a two-step process accomplished by two groups of autotrophic bacteria under aerobic conditions. Ammonia is first oxidized to nitrite by Nitrosomonas sp., and nitrite is further catalyzed to nitrate by Nitrobacter $s p$.. Nitrate formation is normally regarded as the rate-limiting step in nitrification. During denitrification, nitrate is converted to molecular nitrogen in the presence of heterotrophic bacteria under anoxic conditions. Simultaneously to nitrogen biological removal, organic matter biodegradation, catalyzed by heterotrophic bacteria, should be carried on

Phenol biodegradation takes some efforts from literature since it shows inhibitory effects on microbial population. Most of them are conducted using a pure culture of Pseudomonas putida to determine such effect. Inhibitions of metabolic intermediates of phenol degradation (Wang and Loh, 1999) and of cell growth (Zhu et al., 2000) were verified in high initial phenol concentrations (over $100 \mathrm{ppm}$ ). Some parameters for constant inhibition $\left(\mathrm{K}_{\mathrm{i}}\right)$ in Haldane equation lead to values between $54.1 \mathrm{ppm}$ (Monteiro et al., 2000) and 348 ppm (Goudar et al., 2000), demonstrating that these effects are significant to be under-estimated.

In wastewater technology the principles of sequencing batch reactors (SBR) operated in a fill-and-draw mode have been known from the very beginning of the activated sludge process. Since the extensive research in the 70's, SBR have become a quite common modification of activated sludge process (Wanner, 1992). An SBR's cycle involves five operational phases described as fill, react, settle, decant and idle/waste sludge (Norcross, 1992). The hallmark of SBR design is its inherent flexibility of cyclic phasing, providing different operating modes.

The aim of this work was to apply an experimental strategy previously developed for a bench-scale SBR, treating only ammoniacal nitrogen, to a refinery wastewater where phenol is present as a way to minimize both pollutants. Different concentrations were considered to verify inhibitory effects as well as biomass settle ability.

\section{MATERIALS AND METHODS}

\section{EXPERIMENTAL SET-UP}

Heterogeneous microorganisms in the reactor were gradually acclimated to incremental phenol concentrations over a period of time. The experimental set-up was composed of a well-mixed Sequencing Batch Reactor with a working volume 
of $15 \mathrm{~L}$, at $25^{\circ} \mathrm{C}$ and containing an inoculum's of $5 \mathrm{~L}$ approximately. The reactor was operated on a fill-and-draw basis, with a cycle of 360 minutes consisting of 260 minutes in aerobic condition and the last 100 minutes in anoxic one. The reactor was filled along the cycle employing a flow rate of $3 \mathrm{~L} / \mathrm{h}$. This strategy was based on Souza (2000). All experiments were conducted two times, at least.

The synthetic wastewater composition used was characterized as: $\mathrm{NH}_{4} \mathrm{Cl}-76.1 \mathrm{mg} / \mathrm{L} ; \mathrm{Na}_{2} \mathrm{HPO}_{4} .12 \mathrm{H}_{2} \mathrm{O}-46.2$ $\mathrm{mg} / \mathrm{L} ; \mathrm{NaCl}-10.1 \mathrm{mg} / \mathrm{L} ; \mathrm{KCl}-4.7 \mathrm{mg} / \mathrm{L} ; \mathrm{CaCl}_{2} . \mathrm{H}_{2} \mathrm{O}-4.7 \mathrm{mg} / \mathrm{L}$; $\mathrm{MgSO}_{4} .7 \mathrm{H}_{2} \mathrm{O}-16.7 \mathrm{mg} / \mathrm{L} ; \mathrm{NaHCO}_{3}-243.3 \mathrm{mg} / \mathrm{L} ; \mathrm{Na}_{2} \mathrm{CO}_{3}-$ $162.2 \mathrm{mg} / \mathrm{L}$; glucose $-300 \mathrm{mg} / \mathrm{L}$. For biomass maintenance, trace elements $\left(\mathrm{Fe}_{2} \mathrm{Cl} 3.6 \mathrm{H}_{2} \mathrm{O}, \mathrm{ZnSO}_{4}, \mathrm{MnSO}_{4} \cdot \mathrm{H}_{2} \mathrm{O}, \mathrm{CuSO}_{4}\right)$ were added in lower concentrations (less than $0.2 \mathrm{mg} / \mathrm{L}$ ). Phenol was added in a range of 10 to $100 \mathrm{ppm}$. Typical concentrations of initial biomass were determined as 4180 - 8310 ppm Volatile Suspended Solids.

\section{ON LINE MEASUREMENTS AND DATA ACQUISITION}

A microcomputer for supervisory control, a feeding system, an agitation device and an oxygen supply were interfaced with the SBR. A multi-loop controller (CD-600, Smar) was used to monitoring temperature (PT-100 model, Smar), level (LD301 model, Smar), pH (MPH-BN model, Actron), dissolved oxygen (OXY300 model, Danfoss) and redox potential (MOR$\mathrm{BN}$ model, Actron). Commercial supervisory control software
(FIX-DMACS MMI version 6.2, The Intellution Inc.) was available for real-time database management and on-line display of process variables, as shown in Figure 1.

\section{OFF-LINE MEASUREMENTS}

All off-line measurements followed the Standard Methods for the Examination of Water and Wastewater (American Public Health Association, 1992) and were determined three times. Samples were analyzed for phenol, $\mathrm{NH}_{4}^{+}$ and $\mathrm{NO}_{3}$ - concentrations, Chemical Oxygen Demand (COD) and Volatile Suspended Solids (VSS). For substrate concentration determinations, samples were treated by centrifugation process for solids separation. Also the sludge volume index (SVI) was determined. All determinations were carried on in duplicate.

\section{MICROSCOPY}

Samples were taken during a SBR cycle to determine biomass microscopic characteristics. As a capture image system was employed a digital camera coupled to an optical microscopy (Nikon). Phenomena's like de-flocculation were evaluated using these digital images $(400 \mathrm{x})$.

\section{RESULTS AND DISCUSSION}

The results obtained for experiments of phenol biodegradation in distinct initial concentrations are presented

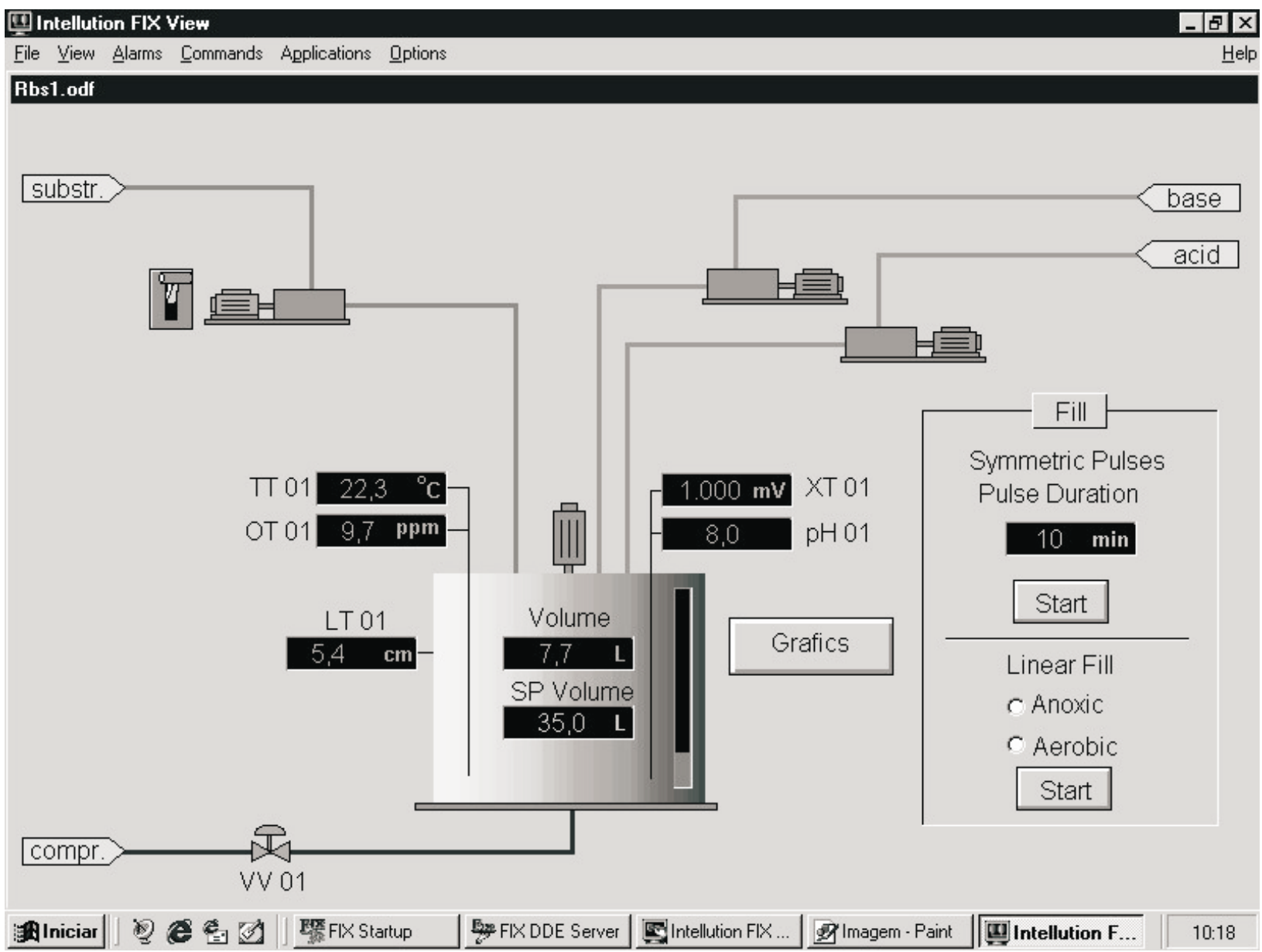

Fig. 1 - Supervisory control: measurements and operatiom coordinates 
below. Figures 2 and 3 present on-line data obtained for $\mathrm{pH}$ and dissolved oxygen by the supervisory software control employed. It is possible to verify that in all experiments both parameters had similar evolution between each situation analyzed, denoting good set-up reproductivity.

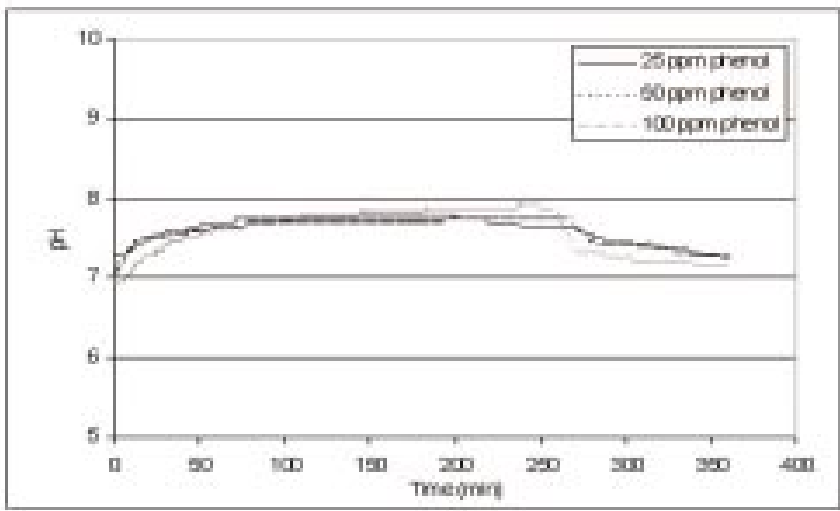

Fig. 2 - pH profiles for different phenol initial concentrations.

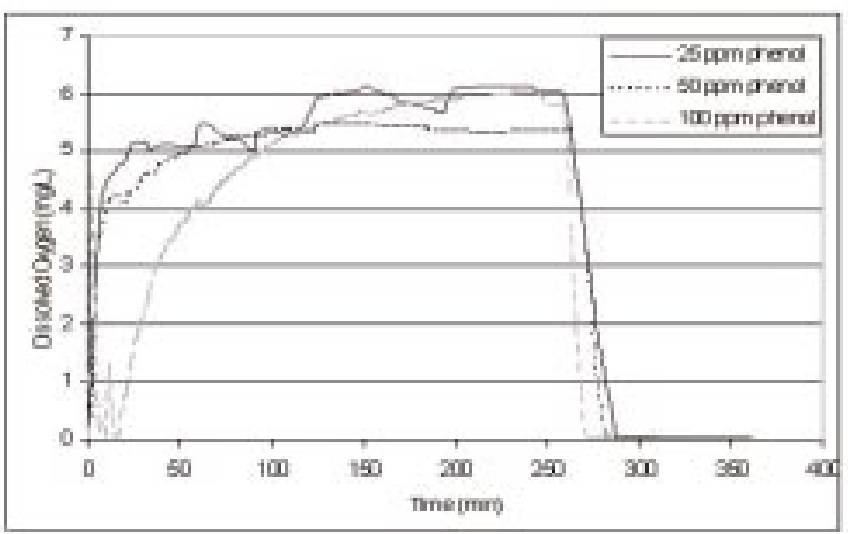

Fig. 3 - Dissolved oxygen utilization during experiments with different phenol initial concentrations.

For the $\mathrm{pH}$ profiles described in Figure 2 is observed a small decline after aeration suppression (in 260 minutes). Despite of this, the values achieved were compatible for cells physiological activity. From oxygen dissolved kinetics is permitted to infer about microbial activity, leading to conclude that this activity is related to initial concentrations of phenol. Figure 3 demonstrates that the time necessary for medium saturation in dissolved oxygen is higher at phenol initial concentrations equal to $100 \mathrm{ppm}$. Similarly, the data shows a quickly decrease obtained for this condition, when the aeration is suppressed. It seems an acceleration of cells metabolism.

Table 1 presents biodegradation index for both ammoniacal nitrogen and phenol in different conditions studied. Referring to ammonia removal is pertinent to detail that biomass adaptation is successively done. It means that microbial enzymatic system is being prepared from lower to higher phenol concentrations. In all cases, a period of at least 7 days was used for this acclimation process between changes in concentration. This experimental strategy could lead to the profiles obtained for removal of $25 \mathrm{ppm}$ of ammoniacal nitrogen presented on Figure 4. Is possible that successive biomass adaptation provides higher biodegradation index and lower concentrations in SBR. Also, as soon as carbon availability is increased with higher initial contents of phenol, a significant biomass growth is expected and, consequently, higher nitrogen utilization for protein synthesis among others metabolic pathways.

As can be observed from Table 1, increases in initial phenol content from 50 to $100 \mathrm{ppm}$, provides a small decline on process performance which may indicates a initial step of process inhibition for biological nitrogen removal. Nevertheless, it is necessary to conduct experiments with higher phenol contents to confirm this possibility.

\begin{tabular}{c|c|c}
\hline Condition Applied (initial phenol content) & Ammonia Removal (\%) & Phenol Removal (\%) \\
\hline $25 \mathrm{ppm}$ & 62.7 & 99.4 \\
\hline $50 \mathrm{ppm}$ & 95.1 & 99.4 \\
\hline $100 \mathrm{ppm}$ & 92.5 & 99.7 \\
\hline
\end{tabular}

Table 1 - Biodegradation index for ammonia and phenol in different conditions studied.

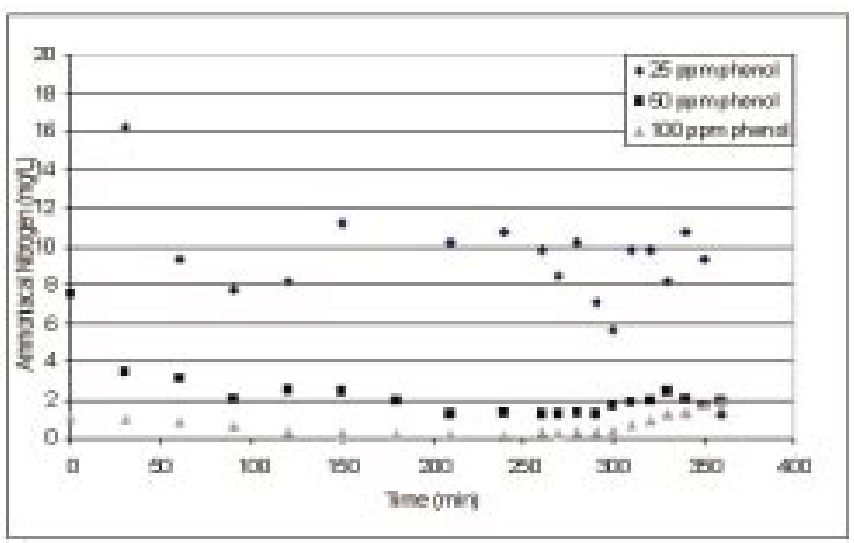

Fig. 4 - Ammoniacal nitrogen removal under different phenol initial concentrations.

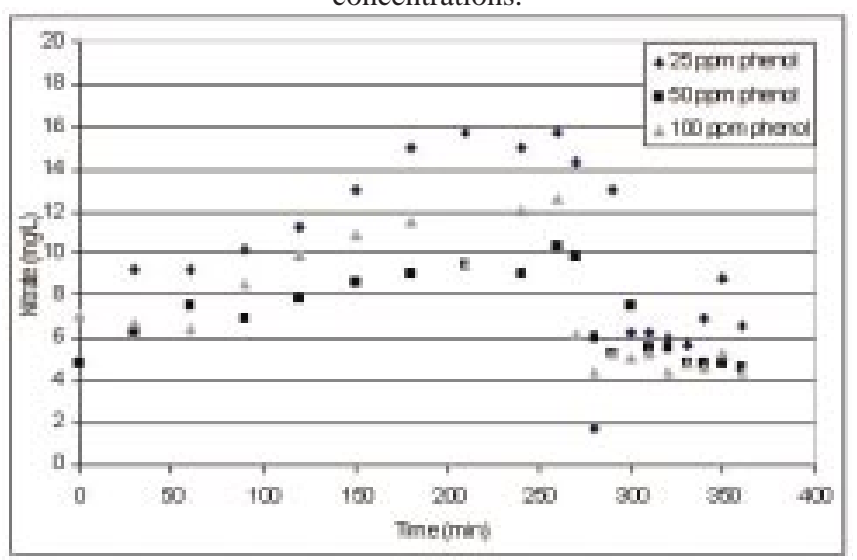

Fig. 5 - Nitrate profiles obtained for different phenol initial concentrations.

Wastewater containing phenol seems no inhibitory effect in nitrate removal. Figure 5 demonstrates clearly an initial step of nitrification process till 260 minutes, where nitrate is formed by ammonia oxidation. In sequence, denitrification begins lowering nitrate contents in SBR. Final nitrate concentrations are according to the Brazilian discharge legislation (lower than $10 \mathrm{ppm}$ ).

For phenol biodegradation is possible to conclude that no significant inhibition on removal process is detected, as presented in Table 1 and Figure 6. The phenol range was chosen based on Morita's work (1993) where refinery wastewater usually contains at maximum $100 \mathrm{ppm}$ in phenol. Final phenol concentrations obtained were similar to that permitted for discharge by law. 


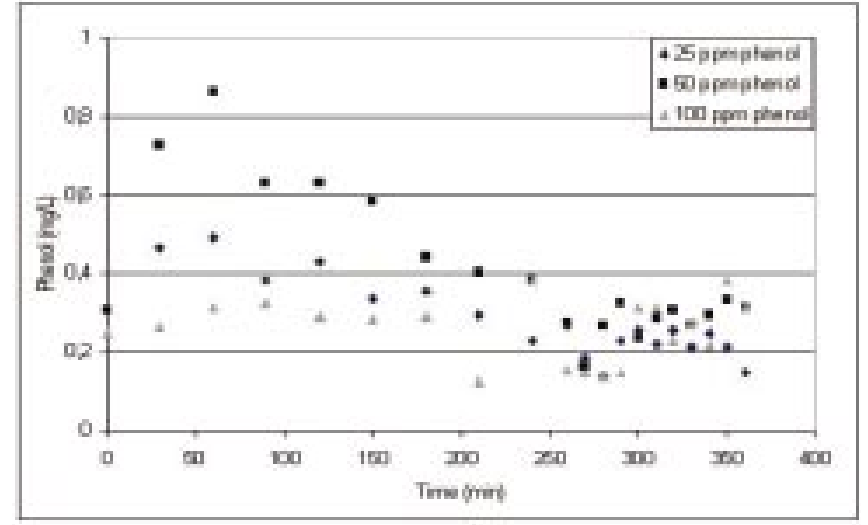

Fig. 6 - Phenol removal in a SBR cycle.

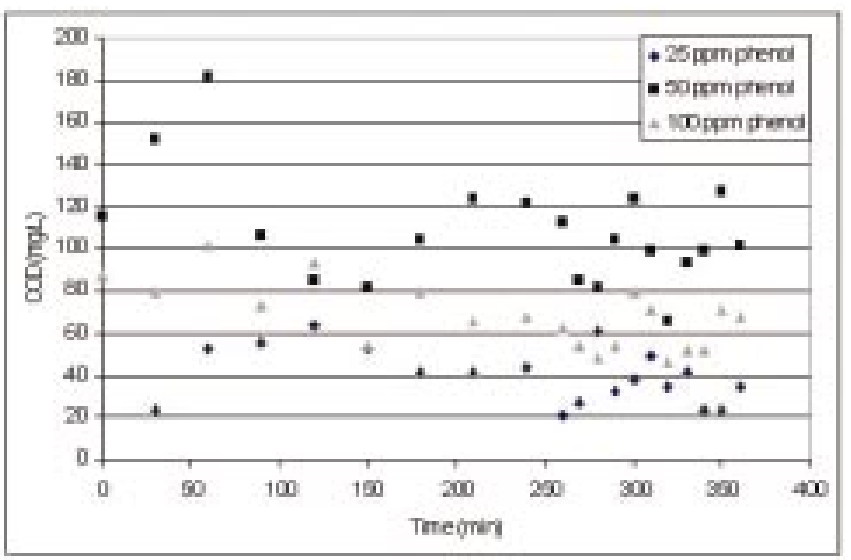

Fig. 7 - COD profiles under different phenol initial concentrations.

The total organic load present in the system is usually given by easily biodegradable substances, like glucose, and by others less susceptible as phenol. Additionally, substances non-biodegradable are computed in COD analysis. Figure 7 presents higher levels for this parameter, demonstrating that other substances could form it as soon as phenol is adequately removed from the wastewater.

\section{MICROSCOPY}

Figures 8.a to 8.d demonstrates microscopic analysis of microbial population at different phenol concentrations. In activated sludge process, a variety of organisms are responsible for process performance, like bacteria, filamentous fungus, yeast and protozoa. Some protozoa could be found in lower phenol concentrations. Nevertheless it seems to disappear as soon as this concentration becomes higher, indicating that activated sludge is being affected by presence of phenol.

According to Vazollér (1989), activated sludge systems are often originated by filamentous bacteria that promote aggregation and consequent flocculation. This property is crucial for activated sludge systems living in a SBR, since its batch scheduling is composed by a sedimentation step before a new cycle. The presence of phenol in wastewater indicates differences in flocculation. Comparing Figures 8.a to 8.d, is possible to verify that those flocks are less compacted at major concentrations, being more dispersed at $100 \mathrm{mg} / \mathrm{L}$ of phenol.

Figure 9 presents a comparison between sludge volume indexes determined in these different situations. Alterations in

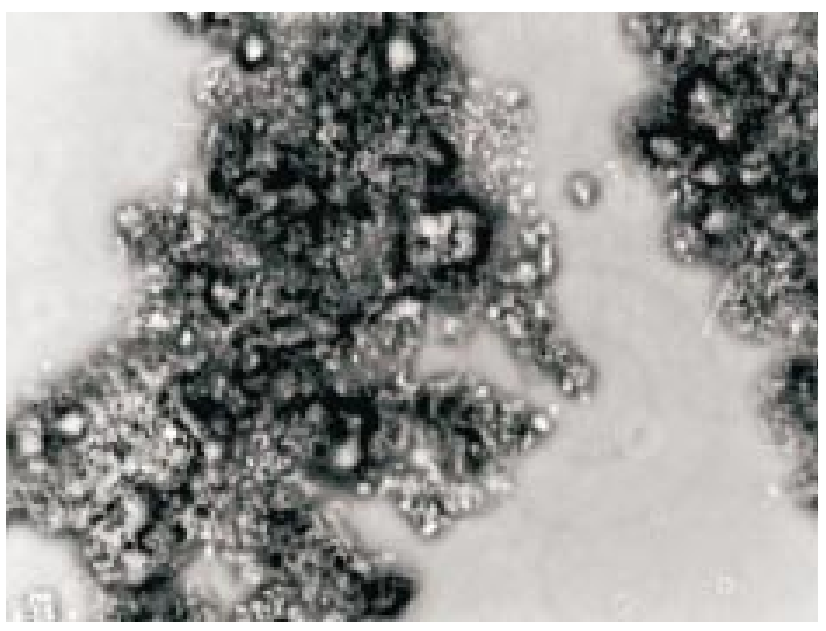

Fig. 8.a - Microscopy observation for sludge at phenol absence, .i.e., initial system

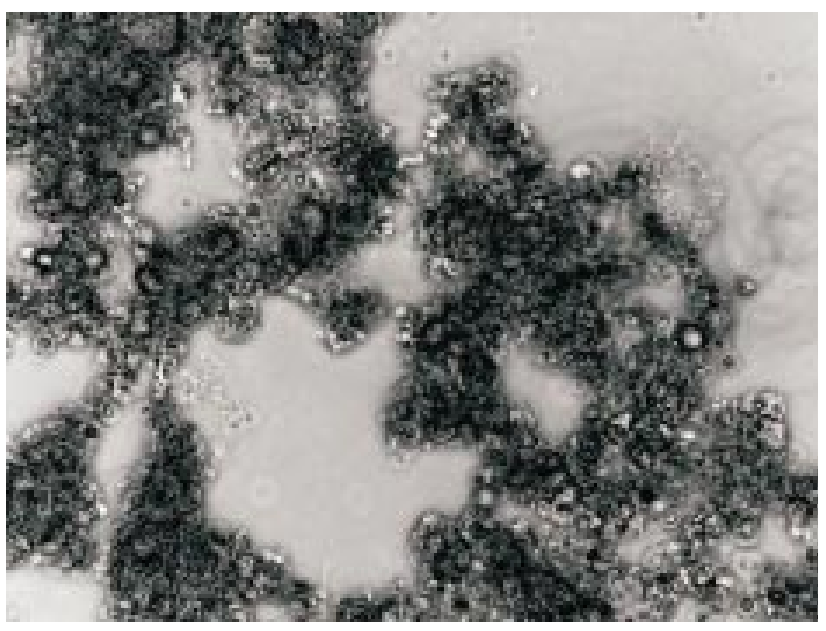

Fig. 8.b - Microscopy observation for sludge at $25 \mathrm{ppm}$ phenol in wastewater.

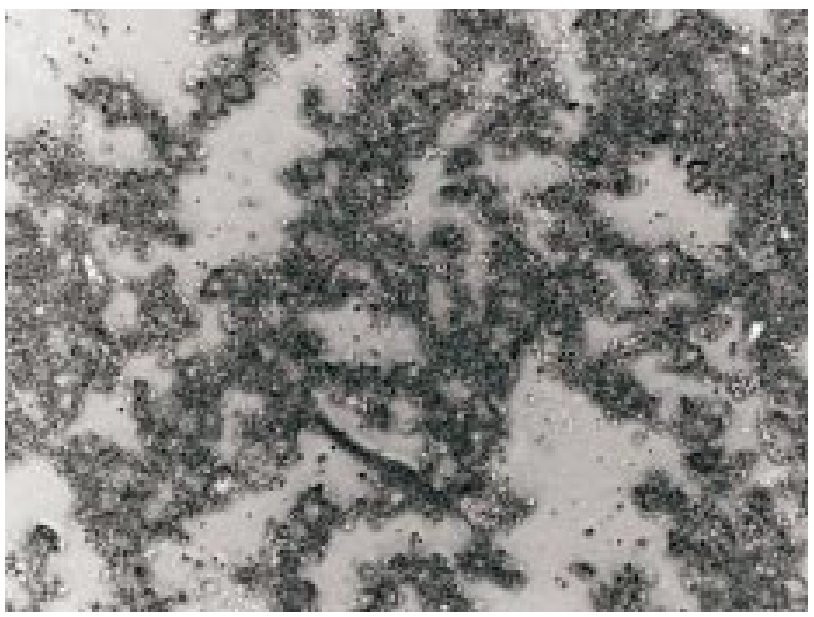

Fig. 8.c - Microscopy observation for sludge at $50 \mathrm{ppm}$ phenol in wastewater. 


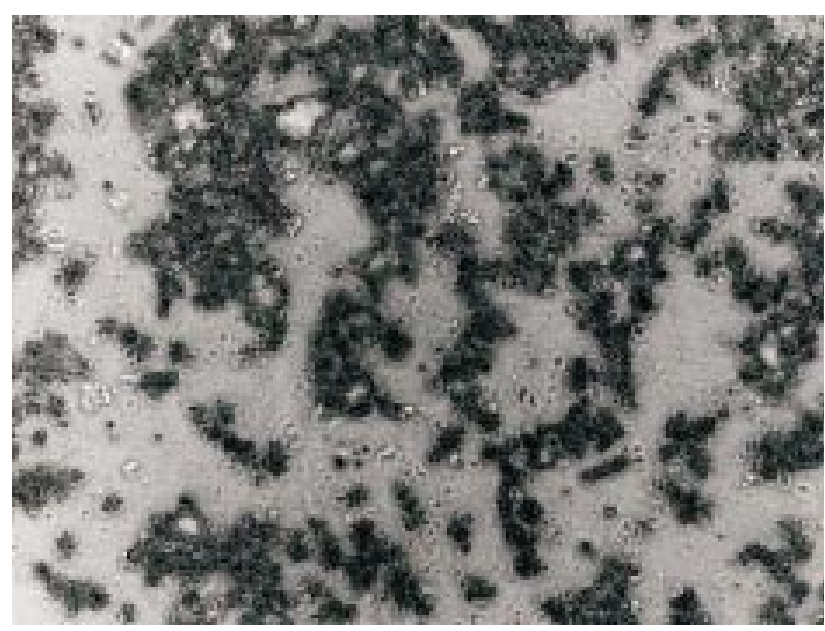

Fig. 8.d - Microscopy observation for sludge at $10 \mathrm{ppm}$ phenol in wastewater.

values of this parameter can be caused by the presence of toxic compounds, like phenol, and it indicates the process ability to separate soluble solids from treated wastewater. Although the sludge volume indexes presented were in the range characterized as good for settle ability $(80<\mathrm{IVL}<150 \mathrm{~mL} / \mathrm{g})$ in current literature, the profile obtained shows a clear exponential trend which lead to infer that in higher phenol concentrations the limit range will be achieved, deteriorating sedimentation performance.

\section{CONCLUSIONS}

The experimental set-up employed in this work, an instrumented Sequencing Batch Reactor, proved to be

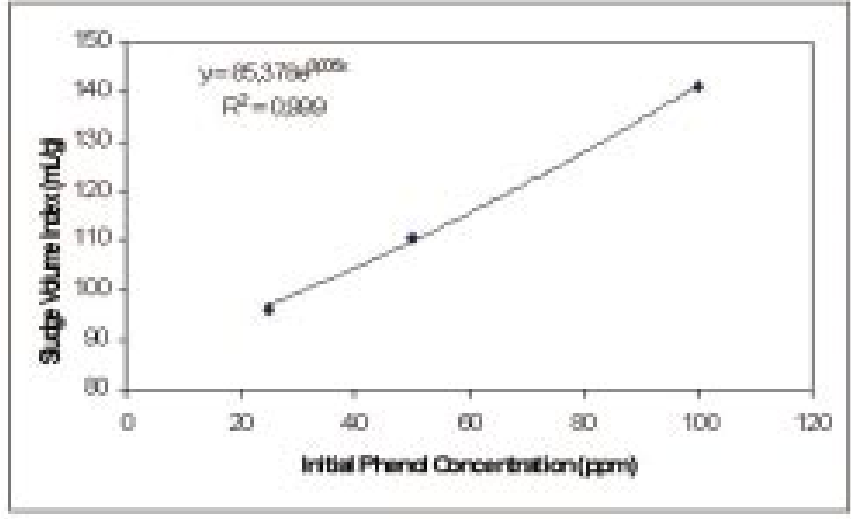

Fig. 9 - Sludge volume index for each condition applied to SBR.

reproducible, considering on-line information about $\mathrm{pH}$ and oxygen dissolved. The batch scheduling applied to biological nitrogen removal demonstrates to be useful for phenol biodegradation in a SBR. Indexes around $95 \%$ and $99 \%$ were achieved for both pollutants degradation. This operational strategy permitted to reach final concentrations allowed by law to be directly discharged.

Successive biomass adaptation showed to prepare microbial enzymatic system for higher contents of pollutants. Nevertheless, phenol presence in wastewater leads to sludge dispersion, especially at higher contents. It could be demonstrated by macro (sludge volume index) and microscopic ways.

\section{REFERENCES}

American Public Health Association. In Standard Methods for Examination of Water and Wastewater; Greenberg, A.E.; Clesceri, L.S. and Eaton, A.D., Eds., 18 $8^{\text {th }}$ ed., USA, 1992.

Goudar, C.T.; Ganji, S.H.; Pujar, B.G.; Strevett, K.A., Wat. Environ. Res., 2000, 72 (1), 50.

Monteiro, A.A.M.G.; Boaventura, R.A.R.; Rodrigues, A.E.; Biochem. Eng. J., 2000, 6 (1), 45.

Morita, D.M., Tese de Doutorado, São Paulo - SP, 1993.

Norcross, K.L.; Wat. Sci. Tech., 1992, 26 (9-11), 2523.
Souza, S.G.M.; Dissertação de Mestrado; UFRJ, Rio de Janeiro - RJ, 2000.

Vazollér, R.F. In Microbiologia de Lodos Ativados, Ed.CETESB, São Paulo, 1989; p 23.

Wang, S.J.; Loh, K.C.; Enz. Microb. Techn., 1999, 25 (3-5), 177.

Wanner J.; Wat. Sci. Tech., 1992, 25 (6), 239.

Zhu, G.H.; Chung, T.S.; Loh, K.C.; J. Appl. Polym. Sci., 2000, 76 (5), 695 